\title{
INFLUENCERS OF HEALTH CARE WASTE GENERATION AT ENHLAZENI DISTRICT MUNICIPALITY, SOUTH AFRICA
}

\author{
M. MACHATE ${ }^{1}$, LZ. MADUNA ${ }^{2}$, K. SEMENYA ${ }^{1} \&$ NDL. THABETHE $^{1}$ \\ ${ }^{1}$ Department of Environmental Sciences, Florida Park Science Campus, University of South Africa, Republic of \\ South Africa \\ ${ }^{2}$ Department of Civil and Chemical Engineering, Florida Park Science Campus, University of South Africa, \\ Republic of South Africa
}

\begin{abstract}
Healthcare waste $(\mathrm{HCW})$ generation is influenced by myriad of factors. This paper presents empirical results on the factors that influence health care waste generation at Ehlanzeni District Municipality. In assessing these factors, the paper begins by examining the concept of $\mathrm{HCW}$, their implication and classification criteria. Empirical data from 57 healthcare facilities were collected and analysed through descriptive and inferential statistics. The findings of this study confirmed, among others that the number of patients served per day (inpatients and outpatients), the number of personnel (staff), have an influence on the amount of $\mathrm{HCW}$ generated per day per $\mathrm{kg}$, at different correlational levels. The number of patients served per day have proved a strong correlation with the amount of HCW generated per day per kg, as compared to the number of personnel. Among other findings, the study revealed that there are numerous factors that influence HCW generation at varying the degrees.

Keywords: healthcare waste, healthcare waste definitions, healthcare waste management, general healthcare waste, hazardous healthcare waste.
\end{abstract}

\section{INTRODUCTION}

The generation of healthcare waste (HCW) cannot be completely avoided because according to Choudhary and Slathia (2014), healthcare is an essential aspect of life. Instead, HCW should be efficiently managed. Firstly, this paper examines the concept of HCW. According to Bendjoudi, Taleb, Abdelmalek and Addou (2009), 'there are currently several terms used to describe waste that is generated from healthcare facilities' as confirmed by World Health Organisation (WHO, 1999;2004). Muhwezi et al (2014) confirm the previous findings by World Health Organisation (WHO, 1999;2004) and Bendjoudi et al (2009), that there has been some level of inconsistences about what is defined or characterise as HCW, globally. This paper attempts to firstly interrogate the common concepts that are interchangeably use for HWC. Not only is HCW inconsistently defined, but global studies show that there are different concepts used for HCW in different regions of the world namely, (1) biomedical waste, (2) medical waste, (3) hospital waste and (4) clinical waste. In Fig. 1, the frequency global studies that use either of the concepts interchangeably to HCW is presented.

According to Fig. 1, there are five key concepts fluently used for HCW stream. The frequency of choice of concepts appears to vary continentally. The second argument presented in this study is the sub-classification of HCW based on different groupings or categories. According to Minoglou and Komilis (2018), the most basic criteria for the classification of HCW is to differentiate between hazardous (infectious) and non-hazardous (non-infectious) categories. The non-hazardous fractions are also called general waste or non-infectious waste. According to Mohseni-Bandpei et al (2019), primarily, HCW classification criterion is characterised by the potentially infectious nature and toxicity of the waste materials or their components (Table 1). 


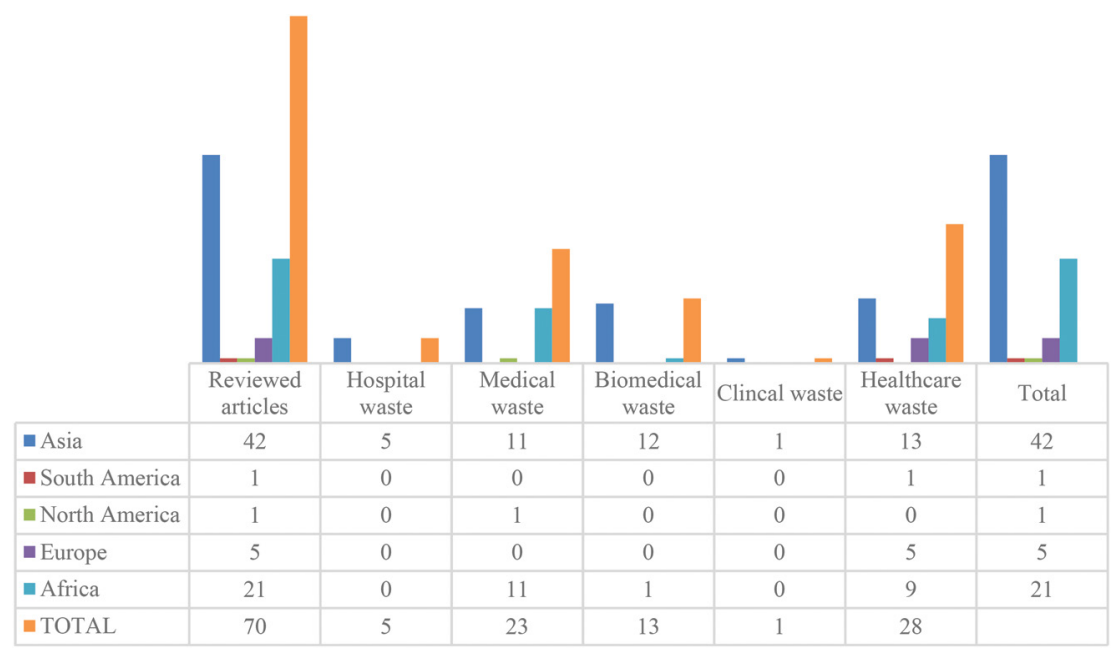

Figure 1: Frequently used concept of $\mathrm{HCW}$ in five continents

Table 1: Ratio of general and infectious waste within HCW.

\begin{tabular}{|c|c|c|c|}
\hline Author & Study area & General (\%) & Hazardous $(\%)$ \\
\hline Mazloomi et al (2019) & Iran & 37 & 63 \\
\hline Aung, Luan \& Xu (2019) & Switzerland & 82.50 & 17.50 \\
\hline Aung, Luan \& Xu (2019) & Myanmar: Yangon & 29 & 71 \\
\hline Aung, Luan \& Xu (2019) & Myanmar: Mandalay & 17 & 83 \\
\hline Aung, Luan \& Xu (2019) & $\begin{array}{l}\text { Myanmar: } \\
\text { Naypyidaw }\end{array}$ & 30 & 70 \\
\hline $\begin{array}{l}\text { Bhalla, Bandyopadhyay \& } \\
\text { Sahai (2018) }\end{array}$ & India & 82.50 & 17.50 \\
\hline Minoglou \& Komilis (2018) & Greece & 80 & 20 \\
\hline $\begin{array}{l}\text { Hameed, Riaz, Minallah \& } \\
\text { Munawar (2017) }\end{array}$ & Pakistan - Public & 85 & 15 \\
\hline $\begin{array}{l}\text { Hameed, Riaz, Minallah \& } \\
\text { Munawar (2017) }\end{array}$ & Pakistan - Private & 86 & 14 \\
\hline $\begin{array}{l}\text { Hameed, Riaz, Minallah \& } \\
\text { Munawar (2017) }\end{array}$ & $\begin{array}{l}\text { Pakistan - Semi } \\
\text { Government }\end{array}$ & 84 & 16 \\
\hline $\begin{array}{l}\text { Hameed, Riaz, Minallah \& } \\
\text { Munawar (2017) }\end{array}$ & Pakistan- Trust & 86 & 14 \\
\hline $\begin{array}{l}\text { Nemathaga, Maringa \& } \\
\text { Chimuka (2008) }\end{array}$ & South Africa & 61 & 39 \\
\hline $\begin{array}{l}\text { Mbarki, Kabbachi, Ezaidi \& } \\
\text { Benssaou (2013) }\end{array}$ & Morocco & 70 & 30 \\
\hline
\end{tabular}


The data in Table 1 show a range of $14 \%$ to $83 \%$ of the HCW being infectious, while $17 \%$ to $86 \%$ is general. On average, $36 \%$ of the waste materials are infectious as compared to $64 \%$ of general components, at $26 \%$ standard deviation. Half (median) of the data facilities generated 20\% infectious and 80\% non-infectious waste. Most of the data sources reported $18 \%$ and $83 \%$, infectious and non-infectious waste fractions, respectively.

Secondly the classification of HCW is broadly categorised as infectious and non-infectious. These categories are further sub-classified according to their material composition. For example, according to Mishra et al. (2016) and Mazloomi et al. (2018), infectious waste is sub-categorised into pathological, pharmaceutical and chemical properties. It is noted from this discussion that as discussed earlier, some regions of the world have adopted their HCW concepts from the different $\mathrm{HCW}$ characterization classes, while others use the broad category than a sub-category (Acharya et al., 2014). Furthermore, USEPA (2011), Windfield and Brooks (2015), Mazloomi et al (2018) support a view that each HCW category at different classification levels may take either solid, liquid, gaseous state or a combination thereof.

Thirdly and most importantly, this study examined the factors that influence the generation of the HCW stream. Komilis, Fouki and Papadopoulos (2012), concluded that different categories of healthcare facilities drive HCW generation. Patwary, O'Hare, Street, Elahi, Hossain and Sarker (2009), identified the size and location of the healthcare facility as the second factor that influence the generation of HCW . In their study, Ptawary et al (2009) concluded that 'the amount of waste, and the proportion of hazardous waste varied significantly with the size and type of healthcare centres. Tabasi and Marthandan (2013) and Eker and Bilgili (2011) agree that the number of patients influence HCW generation. Thus, Eker and Bilgili (2011), argue that 'the generated waste quantities can be affected by the inpatient numbers and so the waste quantities from healthcare services can be evaluated using the number of patients visiting the healthcare facility per day. Hence, Eker and Bilgili (2011), suggest that an evaluation of the HCW generation rates can be done by determining the number of the visitors or both out and inpatients that visit a healthcare facility.

Tabasi and Marthandan (2013), identified (1) number of beds, (2) bed occupancy rates and (3) the type of hospitals or healthcare facility, as key drivers of HCW generation rate. There is some level of consensus about several factors that influence HCW generation ,that is evident from Cheng, Sung, Yang and Chung (2009) who concur that (1) the number of beds; (2) number of speciality beds, (3) bed occupancy, (4) number of infectious disease beds, (5) number of outpatients per day, (6) amount of waste recycled and (7) the proportion of patients treated per day influence HCW. Consequently, this paper reports on the influence of a selected number of common factors among the above discussed. A study from Irbid City by Bdour et al (2007), proved that public hospitals with equal numbers of beds, patients serve per day and staff numbers produced $6.1 \mathrm{~kg}$ of $\mathrm{HCW}$ per bed per day as compared to $4.02 \mathrm{~kg}$ in a private hospital of similar status and capacity. In another study in Taiwan, Cheng et al (2009) confirmed the influence of number of beds, bed occupancy rate and related factors on HCW generation rate. Shakiba and Mohagheghian (2018), Alwabr et al (2016), Hayleeyesus and Cherinete (2016), Aseweh (2013), Ali et al (2016), Khajuria et al (2007) and Pandey et al (2016) concur with the above factors as drivers of HCW generation rates. In this variability (Table 2), the efficiency of healthcare facility's production systems (including that of individual personnel) and the levels of developments in the study area emerge as other factors that influence $\mathrm{HCW}$ generation rates. 
Table 2: Healthcare waste generation rate per kilogram per patient per day.

\begin{tabular}{|c|c|c|}
\hline Author & Study area & $\begin{array}{l}\text { Generation rate per kg per pa- } \\
\text { tient per day }\end{array}$ \\
\hline Tesfahun et al., 2016 & Ethiopia & 0.245 \\
\hline Rabeie et al., 2012 & Iran & 3.1 \\
\hline Eker et al., 2011 & Turkey & 3.83 \\
\hline Eleyan et al., 2013 & Palestine & 0.4 \\
\hline Maamari et al., 2015 & Lebanon & 2.45 \\
\hline Gusca et al., 2015 & Kazakhstan & 0.814 \\
\hline Patwary et al., 2009 & Bangladesh & 0.499 \\
\hline Yong et al., 2009 & China & 0.65 \\
\hline Patil \& Shekdar., 2001 & India & 1.5 \\
\hline Jang et al., 2006 & Korea & 1.3 \\
\hline Phengxay et al., 2005 & Japan & 0.62 \\
\hline Adsavakulchai et al., 2002 & Thailand & 0.4 \\
\hline Yelebe et al., 2015 & Nigeria & 0.18 \\
\hline Hassan et al., 2018 & Sudan & 0.6 \\
\hline Askarian et al., 2010 & Iran & 5.92 \\
\hline Hameed et al., 2017 & Pakistan & 1.28 \\
\hline Bdour et al 2005 & Irbid City & 6.1 \\
\hline Bdour et al 2006 & Irbid City & 5.62 \\
\hline Bdour et al 2007 & Irbid City & 4.02 \\
\hline Abah & Nigeria & 0.62 \\
\hline Abah & Nigeria & 0.63 \\
\hline Mbarki et al 2013 & Morocco & 0.53 \\
\hline Mean (Average) & & 1.87 \\
\hline Minimum & & 0.18 \\
\hline Maximum & & 6.1 \\
\hline Mode & & 0.4 \\
\hline Median & & 0.73 \\
\hline Standard deviation & & 1.97 \\
\hline
\end{tabular}

From Table 2, it can be deduced that on average, a patient generates $1.87 \mathrm{~kg}$ of $\mathrm{HCW}$ per day. The generation rate ranges from 0.18 to $6.1 \mathrm{~kg}$ per patient per day, at $1.97 \mathrm{~kg}$ standard deviation. Most studies found a $0.4 \mathrm{~kg}$ generation rate per patient per day, while half of the reviewed studies per patient $\mathrm{HCW}$ generation rate was $0.73 \mathrm{~kg}$. 


\section{MATERIALS AND METHODS}

A survey was used carried out in selected 57 private and public health care facilities in Enhlazeni district. All questions were based on the variables of interest of the study and their related sub-variables (Mouton, 2013). Descriptive statistics were used to organise, summarise and present data, as recommended by Keller (2014). The data and information were thus presented using graphs and numerical techniques such as the calculation of central and variability measures (Creswell, 2009). Furthermore, inferential statistics were used to draw conclusions and inference about the relationship between the number of patients served per day and personnel correlated with the amount of $\mathrm{HCW}$ generated per day per kg. further analysis of the efficiency profiles of the 57 healthcare facilities (which were randomly selected from a list of existing facilities) were also done through observation of the peak points of a threelined graph. Empirical results were analysed and compared with the findings of the literaturebased analyses. Microsoft Excel 2013 was used for all statistical calculations. Lastly, to analyse some qualitative data, an explanatory analysis was used (Gibbs, 2007; Creswell, 2009).

\section{DISCUSSION OF RESULTS}

Empirical data was collected from 57 healthcare facilities which are private and public, constituting different categories, different operations and sizes that generate waste stream that falls within the definition of HCW (Fig. 2).

The empirical results in Fig. 2 identify hospitals, clinics, pharmacies, healthcare centres, medical practices and specialised medical centres or facilities as primary HCW generators within Ehlanzeni District Municipality. These facilities vary in sampled numbers and are further classified into private and public. In Fig. 3, the association between the number of healthcare staff (all-inclusive) and the HCW generation rate per day are tested. Table 3 presents the key central and dispersion measures of the number of staff, patients per day, operational days of a healthcare facility per week, the amount of HCW generated per week per kg (general, infectious and combined).

Comparatively analysis (where possible) of HCW generation quantities and rates in Tables 1,2 and 3 show the variability of generations across many variables and parameters. Figure 3 presents the influence of staff numbers on HCW generation per kg per week.

Empirical data confirms that the number of patients that the healthcare facilities at Ehlanzeni District Municipality serve per day correlates strongly and positively with the

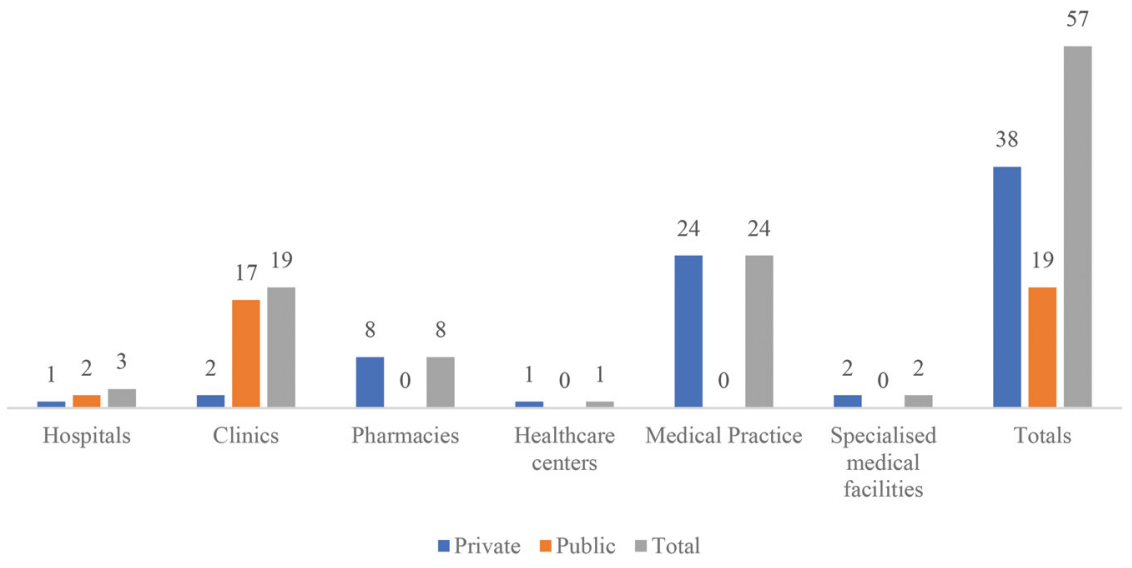

Figure 2: Different categories of healthcare facilities at Ehlanzeni District Municipality. 
Table 3: Descriptive statistical analysis of the number of staff, patients per day, operational days of a healthcare facility per week, the amount of HCW generated per week per kg.

\begin{tabular}{lllllll}
\hline Variables & Mean & Min & Max & Median & Mode & $\begin{array}{l}\text { Standard } \\
\text { deviation }\end{array}$ \\
\hline $\begin{array}{l}\text { Total number of staff per } \\
\text { healthcare facility }\end{array}$ & 54.1 & 1 & 1,188 & 7 & 3 & 192.91 \\
$\begin{array}{l}\text { Number of patients served per } \\
\text { day }\end{array}$ & 135 & 0 & 1,000 & 40 & 10 & 0.79 \\
$\begin{array}{l}\text { Number of operational days } \\
\text { per week }\end{array}$ & 6.14 & 5 & 7 & 6 & 7 & 200.76 \\
$\begin{array}{l}\text { Infectious waste generated per } \\
\text { week per kg }\end{array}$ & 81.7 & 0 & 2,403 & 7.45 & 0 & 347.21 \\
$\begin{array}{l}\text { General waste generated per } \\
\text { week per kg }\end{array}$ & 23.7 & 0 & 1,000 & 1 & 0 & 133.56 \\
$\begin{array}{l}\text { Total waste generated per } \\
\text { week per kg }\end{array}$ & 102.82 & 0 & 3,403 & 11 & 3 & 471.75 \\
\hline
\end{tabular}

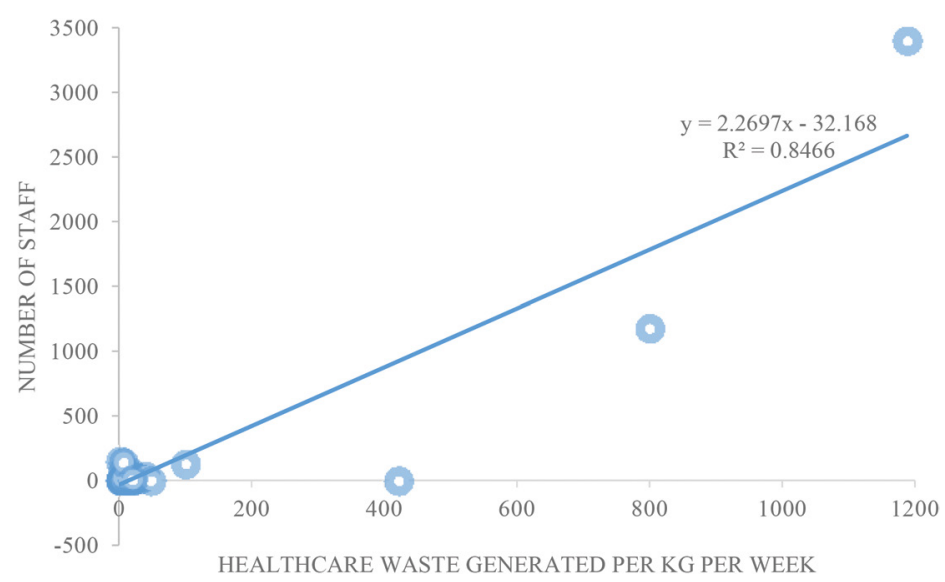

Figure 3: Influence of patient numbers per day on $\mathrm{HCW}$ generation per kg per week.

amount of HCW generated per day at a $R^{2}=0,84$, which is equal to $P=0,84$. In contrast, Fig. 4 presents the contrast with regards to the influence of staff numbers on the amount of HCW generation per day per kilogram.

The correlation between the number of staff and the amount of HCW generated per day per kg proved existent and weak, but positive at $R^{2}=0,81$. Lastly, Fig. 5 displays a comparative analysis among three variables (patients per day, number of staff $\&$ the amount of waste generated per day).

It is evident in Fig. 5, that the increase in staff numbers and patients served per day does not always correspond with the amounts of waste generated per day, as evident from the peak points of each variable. Observing each variable in comparison to the other two per healthcare 


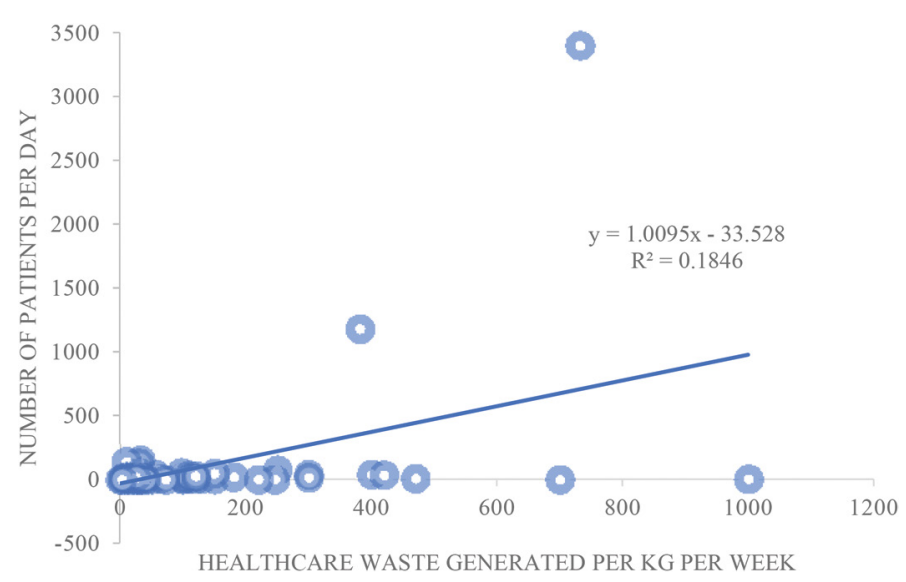

Figure 4: Influence of the total number of staff members on the amount of HCW generated per day per kg per healthcare facility.

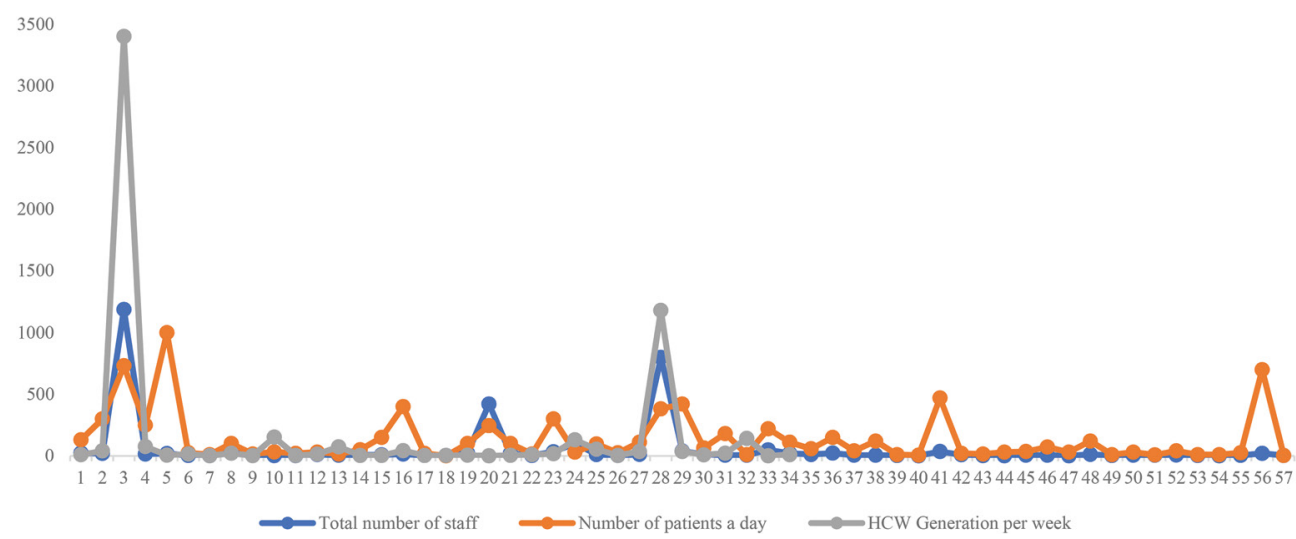

Figure 5: Relationship among number of patients and staff per day and amount of waste generated.

facility, in few instances (at facility 3,10,13,24, 28 and 32) the amount of waste generated per day per kg exceeded the number of patients per day and staff. This observation highlights an increase in waste quantity generated per patient and staff member per $\mathrm{kg}$ per day.

The number of patients in facilities $(1,2,5,8,15,16,19,21,23,25,27,29,30,31,33$, $34,35,36,37,38,41,46,48,50,52$ and 56) is higher than both the number of staff and the amount of $\mathrm{HCW}$ generated per day per $\mathrm{kg}$. from this observation, the identified healthcare facilities are more efficient in their ratio of $\mathrm{HCW}$ generation per served patients per day. This is the most desirable state of production, provided that the quality of service given to each patient remains at its best, as defined by Machete et al (2015). In contrast, healthcare facility number 20 has a high number of staff than the number of patients served per day and the amount of HCW generated per day per kg. from this study, facility 20 appears as the most inefficient healthcare facility of all. 


\section{CONCLUSIONS}

This paper investigated the influence of patient served per day and staff number on health care waste generation at Ehlanzeni District Municipality. Available literature revealed that HCW generation is influenced by myriad of factors, including the number of personnel and patients served per day. Empirical data from the 57 healthcare facilities in Ehlanzeni District Municipality confirmed the influence of number of patients served per day and personnel at varying regression levels. The number of patients served per day have proved a strong correlation with the amount of $\mathrm{HCW}$ generated per day per $\mathrm{kg}$, as compared to the number of personnel. This paper also analysed efficiency levels of healthcare facilities with reference to the ratio of HCW generation against personnel numbers and that of patients served per day. The findings revealed several efficient healthcare facilities, with one extremely inefficient facility.

The findings of this study are important in setting the fundamental base for efficient assessment of HCW generation and identification of factors that drive HCW generation. The knowledge of these factors and their prioritization serve as causation and priority factors that need to be prioritised, if a healthcare facility intends to reduce its waste generation quantities and rates. It also serves as a guideline for prioritization of cost allocation in the prevention of HCW generation budgeting. The comparative analyses of HCW generation rates across various variables between available literature and empirical studies, provide a platform for future scholars to understand the significance of the use of available literature as a baseline for performance assessment, against which performance should be measured.

\section{ACKNOWLEDGEMENTS}

This research was supported by funding from the National Research Foundation: Thuthuka Grant (Grant No.: 121862) and the University of South Africa (UNISA) Community Engagement Project (CU1600).

\section{REFERENCES}

[1] Acharya, A., Gokhale, V.A and Joshi, D. (2014). Impact of Biomedical waste on city Environment: Case Study of Pune India. Journal of Applied Chemistry, 6(6), 21-27.

[2] Alessandra, C. and Belgiorno, V. (2017). "Sustainability of medical waste management in different sized health care facilities." Waste and biomass valorization, 8 (5), 18191827.

[3] Ali, M., Wang, W. and Chaudhry, N., 2016. Management of wastes from hospitals: A case study in Pakistan. Waste Management \& Research, 34(1), pp.87-90.

[4] Alwabr, G.M., Al-Mikhlafi, A.S., Al-Hakimi, S.A. and Dughish, M.A., 2016. Determination of medical waste composition in hospitals of Sana'a city, Yemen. Journal of Applied Sciences and Environmental Management, 20(2), pp.343-347.

[5] Aseweh Abor, P., 2013. Managing healthcare waste in Ghana: a comparative study of public and private hospitals. International journal of health care quality assurance, 26(4), pp.375-386.

[6] Askarian, M., Heidarpoor, P., Assadian, O., 2009. A total quality management approach to healthcare waste management in Namazi Hospital, Iran. Waste Management 30 (2010) 2321-2326.

[7] Awodele, O., Adewoye, A.A. and Oparah, A.C. (2016). Assessment of medical waste management in seven hospitals in Lagos, Nigeria. BMC Public Health, 16 (269). 
[8] Capoor, M.R. and Bhowmik, K.T. (2017). Current perspective on biomedical waste management: rules, conventions and treatment technologies. Indian Journal of Medical Microbiology, 35(2), 157-164.

[9] Creswell JW, Hanson WE, Clark VLP and Morales A. 2009. Qualitative research designs: Selection and implementation, The Counselling Psychologist, 2 (35): 236-264.

[10] Creswell JW. 2009. In: Creswell, J.A. Educational research: Planning, conducting and evaluating quantitative and qualitative research, 3rd Ed. Upper Saddle River, NJ: Pearson Education.

[11] Creswell, J. W., Hanson, W. E., Clark, V. L. P. and Morales, A. (2009). Qualitative research designs: selection and implementation. The Counselling Psychologis, 35, 236264.

[12] Gibbs GR. 2007. Analysing qualitative data, Thousand Oaks, CA: SAGE.

[13] Hameed, K., Riaz, O. U., Minallah, M.N. and Munawar, H. (2017). Types of Hospital Waste and Waste Generation Rate in Different Hospitals of Faisalabad City, Pakistan. Journal of Basic and Applied Sciences, 13, 386-391.

[14] Hayleeyesus, S.F. and Cherinete, W., 2016. Healthcare waste generation and management in public healthcare facilities in Adama, Ethiopia. Journal of Health and Pollution, 6(10), pp.64-73.

[15] Joseph, L. and Paul, H. (2015). Biomedical Waste Management: Study on the awareness and practice among healthcare workers in a tertiary teaching hospital. Indian Journal of Medical Microbiology, 33(1), 129-131.

[16] Keller, G. (2014). Statistics for Management and Economics (10 ed.). Canada: Cengage Learning.

[17] Kumar, R., Gupta, A.K., Aggarwal, A.K. and Kumar, A. (2014). A descriptive study on evaluation of bio-medical waste management in a tertiary care public hospital of North India. Journal of Environmental Health Science \& Engineering, 12(69).

[18] Leedy PD and Ormrod JE. 2010. Practical research: Planning and design, 9th ed. Upper Saddle River, NJ: Merrill Prentice Hall.

[19] Leedy, P. D., \& Ormrod, J. E. (2010). Practical research planning and design 9th ed. United State of America: Pearson Education Limited.

[20] Machete, F. Hongoro, C, Nhamo, G and Mearns, KF. 2015. Influence of energy saving on the quality of lighting services on selected hotels in Mpumalanga, Republic of South Africa. African Journal of Science, Technology, Innovation and Development. 7 (4) 301-305 http://dx.doi.org/10.1080/20421338.2015.1082369.

[21] Mazloomi, S., Zarei, A., Alavasvan, S., Farhad, D., Nourmoradi, P. and Bonyadi, Z. (2018). Analysis of quality and quantity of health-care wastes in clinical laboratories: a case study of Ilam city. Environmental Monitoring and Assessment, 71, 216-225.

[22] Mbarki, A., Kabbachi, B., Ezaidi, A. and Benssaou, M., 2013. Medical waste management: A case study of the souss-massa-draa region, morocco. Journal of Environmental Protection, 4(9), p.914.

[23] Minoglou, M. and Komilis, D. (2018). Describing health care waste generation rates using regression modeling and principal component analysis. Waste Management, 78, 811-818. 
[24] Mohseni-Bandpei, A., Majlesi, M., Rafiee, M., Nojavan, S., Nowrouz, P. and Zolfagharpour, H. (2019). Polycyclic aromatic hydrocarbons (PAHs) formation during the fast pyrolysis of hazardous health-care waste. Chemosphere, 227, 277-288.

[25] Mouton J. 2013. How to succeed in your masters and doctoral studies: A South African guideline and resource book. Cape Town: Van Schaik.

[26] Mouton, J. (2013). How to succeed in your masters and doctoral studies: A South African guideline and resource book. Cape Town: Van Schaik Publishers.

[27] Muhwezi, L., Kaweesa, P., Kiberu, F. and Eyoku, L. E. (2014). Health care waste management in Uganda: A case study of Soroti regional referral hospital. International Journal of Waste Management and Technology, 2(2), 1-12.

[28] Nemathaga, F., S. Maringa, and L. Chimuka. (2008). "Hospital solid waste management practices in Limpopo Province, South Africa: A case study of two hospitals." Waste Management (New York, N.Y.) 28 (7): 1236-45. doi: 10.1016/j.wasman.2007.03.033. PMID:18060760

[29] Rajan, R., Robin, D.T., Vandanarani, M. (2018). Biomedical waste management in Ayurveda hospitals - current practices \& future prospective. Journal of Ayurveda and Integrative Medicine, XXX, (1-8).

[30] Ramírez, C. and Gonzalez, E. (2019). Methodological proposal for the inter-institutional management of wastes in health care centers in Uruguay. MethodsX, 6, pp.71-81.

[31] Shakiba, M. and Mohagheghian, A., 2018. Hospital waste generation and management status in Rasht, north of Iran. Caspian Journal of Health Research, 3(1), pp.20-23.

[32] William, F., \& Mohamed, S. B. (2012). A guide to managing research. Cape Town: Juta $\&$ Co Ltd.

[33] Windfield, E. and Brooks, M. (2015). Medical waste management - A review. Journal of Environmental Management, 163, 98-108.

[34] World Health Organisation. (2005). Management of solid healthcare waste at primary healthcare centres. A decision-making guide. Geneva: WHO. (ISBN 924 1592475).

[35] Xiao, F. (2018). A novel multi-criteria decision-making method for assessing healthcare waste treatment technologies based on numbers. Engineering Applications of Artificial Intelligence, 71, 216-225.

[36] Cheng, Y.W., Sung,F.C., Yang, Y., Lo, Y.H., Chung, Y.T., Li, K.C. (2009)Medical waste production at hospitals and associated factors. Waste Management, 29, 440-444.

[37] Tabasi, R. and Marthandan, G., 2013. Clinical waste management: A review on important factors in clinical waste generation rate. International Journal of Science and Technology, 3(3), pp.194-200.

[38] Eker, H.H. and Bilgili, M.S., 2011. Statistical analysis of waste generation in healthcare services: a case study. Waste Management \& Research, 29(8), pp.791-796.

[39] Patwary, M.A., O’Hare, W.T., Street, G., Elahi, K.M., Hossain, S.S. and Sarker, M.H., 2009. Quantitative assessment of medical waste generation in the capital city of Bangladesh. Waste management, 29(8), pp.2392-2397.

[40] Komilis, D., Fouki, A. and Papadopoulos, D., 2012. Hazardous medical waste generation rates of different categories of health-care facilities. Waste Management, 32(7), pp.1434-1441.

[41] Jovanovic,V., Jovanovic, D., Matic,B., Djonovic, N. (2016). The influence of healthcare factors on medical waste management in Serbian hospital facilities. 
[42] Hayleeyesus,S.F. and Cherinete, W. (2016). Healthcare Waste Generation and Management in Public Healthcare Facilities in Adama, Ethiopia. Journal of Health Pollution 10: 64-73 (2016).

[43] Debere, M.K., Gelaye, K.A., Alamdo, A.G. and Trifa, Z.M.(2013).Assessment of the health care waste generation rates and its management system in hospitals of Addis Ababa, Ethiopia, 2011. BMC Public Health, 13:28.

[44] Haylamicheal, D.I, Dalvie, A.M, Yirsaw, D.B, Zegeye, A.H (2011). Assessing the management of healthcare waste in Hawassa city, Ethiopia. Waste Management \& Research 29(8) 854-862.

[45] Mato, M. and Kaseva, E. (1999). Critical review of industrial and medical waste practices in Dar es Salaam City. Resources, Conservation and Recycling 25, 271-287. 